\title{
PHYSICAL FITNESS CHARACTERISTICS OF A FRONT-LINE FIREFIGHTER POPULATION
}

\author{
Michael R. Antolini, Zach J. Weston, Peter M. Tiidus \\ Departments of Kinesiology \& Physical Education and Health Sciences, \\ Wilfrid Laurier University, Waterloo ON, Canada
}

\begin{abstract}
Firefighters require a high level of physical fitness in order to meet the demands of their profession. While physical performance testing is required to join the department, firefighters are not subject to further formal exercise or performance testing throughout the duration of their careers. The purpose of the present study was to gather information regarding the physical fitness of front-line Canadian firefighters, to determine whether a testing battery predictive of both performance and future injury risk is viable, and to make recommendations regarding the format of fitness testing and training programs for front-line firefighters. Front-line, career firefighters were tested on a variety of physical fitness measures related to body composition, strength, power, and endurance over three testing sessions. Large ranges of data were found for many of the measures taken and tests performed. Body fat percentage had the most significant correlations with other performance tests while performance in the pushup test and vertical jump correlated strongly with many of the more sophisticated fitness tests. Some firefighters may not possess adequate fitness levels to optimally perform their job responsibilities. Simple field tests may form the basis of predictive testing batteries for both fitness and future injury risk, though further research is needed.
\end{abstract}

Keywords: front-line firefighters; physical fitness; Functional Movement Screen; injury risk; $\mathrm{VO}_{2} \max$ 


\section{INTRODUCTION}

Firefighters are rescue workers, trained extensively in dealing with fire suppression and prevention. In addition, they are often the first-responders to an emergency situation and therefore also trained in both cardiopulmonary resuscitation and first aid [10]. Firefighting involves rescuing trapped victims, suppressing and controlling the spread of the fire, and limiting property and environmental damage. Work conditions often involve very intense and/or prolonged physical effort, often accompanied by extreme heat stress which necessitates a high level of fitness due to the increased heart rates encountered $[17,28]$. During a period of heat stress, perspiration decreases total body water and therefore blood volume, so stroke volume is also decreased, causing an increase in heart rate in order to maintain sufficient cardiac output. This additional strain on the heart requires a greater coronary blood supply and if the coronary arteries are narrowed from preexisting medical conditions (e.g. increased blood lipids) or the heart cannot maintain a sufficient cardiac output to supply oxygenated blood to both the peripheral working muscles and itself, a myocardial infarction may occur [26].

In order to become a firefighter there is a thorough examination and interview process. As there is a high physical fitness level required for firefighters due to the heavy workload and increased risk of cardiovascular incidents [13] arising from heat stress and prolonged intense physical activity $[17,28]$, a physical performance joining test is a component of the hiring process. Interestingly, other than passing the Candidate Physical Ability Test, both the Kitchener and Toronto fire departments do not specify physical fitness guidelines that need to be maintained once employment has been secured. In addition, there are no further formal fitness tests to demonstrate continuing fitness in an active firefighting career, even though firefighting is by its very nature a very physically demanding profession [10]. Early studies of firefighter physical fitness first aimed to determine the metabolic cost of firefighting in terms of oxygen consumption and suggest a standard for aerobic capacity required to adequately perform the job responsibilities. Several independent studies using either a simulated or actual firefighting task have concluded that as a minimum, firefighters should be able to maximally consume $42 \mathrm{ml} \mathrm{O} / \mathrm{kg} / \mathrm{min}[23,29,31]$.

Previous studies examining firefighter fitness often had fragmented testing approaches in the sense that they focused on either aerobic or anaerobic measures but few were comprehensive in measuring a number of variables of physical fitness using the same subject group of firefighters. In addition, 
younger recruits and early-career firefighters are often over-represented in these studies even though active firefighter units tend to encompass a wide range of age and experience [17, 22, 28, 29]. Predictably, these younger samples tend to produce excellent fitness results, however little comprehensive data is currently available for "average" front-line, mid-career samples of firefighters serving an urban area.

The current study was descriptive in nature and aimed to fulfill three objectives. The primary purpose of this study was to gather information on the physical fitness of a front-line firefighter population with a wide range of experience and utilizing a wide battery of tests. A secondary objective was to make a preliminary assessment of whether a testing battery could be developed that predicted performance in some of the more comprehensive and technical tests performed. Lastly, recommendations regarding the format of physical fitness testing and training programs designed specifically for firefighters could be more accurately informed based on findings from this study.

\section{MATERIALS AND METHODS}

\section{Subjects}

This study was conducted at Wilfrid Laurier University, Waterloo ON Canada, in partnership with the Kitchener Fire Department. Written informed consent was obtained from all participants prior to testing and the internal ethical review board of the University reviewed and approved all aspects of study design and recruitment. Eligible participants were active members of the fire suppression unit of the Kitchener Fire Department. Exclusion criteria included having been advised by a medical professional to not participate in vigorous physical activity, not being able to perform all of the physical demands of their job as a result of a musculoskeletal injury, or a positive result on the Physical Activity Readiness Questionnaire (PAR-Q) [9]. A total of 49 active firefighters ( 47 male, 2 female) completed the first session of testing while only 23 participants ( 22 male, 1 female) completed all three sessions of testing.

\section{Procedures}

Potential participants were recruited by way of a letter sent out by the fire department to all active members of the fire suppression unit inviting them to participate in a study looking at various measures related to health and 
fitness. After an initial round of recruitment, a second follow-up letter was distributed and specific fire stations that had low participation rates were targeted for an in-person visit by the researcher.

Testing took place over three sessions, each with unique assessments performed. The first session took place at the fire station and focused mainly on baseline physiological testing. After height and weight were taken, heart rate was measured using a three-lead electrograph and blood pressure measurement of the brachial artery was performed using a sphygmomanometer. Waist circumference was then measured at the superior border of the iliac crest on the right hand side of the body [19]. Skinfold thickness measurements of the biceps, triceps, subscapularis, and iliac crest were used to calculate body fat percentage according to the Durnin-Womersley method [11]. The additional measurement of the medial calf skinfold thickness allowed for determination of the Canadian Physical Activity, Fitness, and Lifestyle Appraisal Healthy Body Composition Score [8]. All five skinfold measurements were landmarked and assessed using standard procedures [11, 14]. Participants then completed the Functional Movement Screen (FMS), a seven-movement assessment used to identify asymmetries and compensatory movements in the kinetic chain of movement patterns [30]. It should be noted that the FMS is not a test of physical fitness, but rather a screening test that may serve as a baseline for comparison to future tests. The final test performed during the first session was the American College of Sports Medicine Pushup Test to assess muscular endurance of the upper-body [1].

The second testing session took place at the University and after being weighed again, participants performed the $60^{\circ}$ abdominal muscle endurance test to assess the endurance of the spinal flexors [20]. Measures of maximum strength for both the lower and upper body were next assessed using a $60^{\circ} / \mathrm{s}$, isokinetic, concentric contraction of the quadriceps and biceps, respectively using a Cybex Norm $[2,16]$. The last assessment performed was the Wingate Anaerobic Test to determine lower-body anaerobic power. A standardized warm-up preceded the maximum effort test consisting of a $30 \mathrm{~s}$ cycle against a heavy resistance set to $7.5 \%$ of the participant's body weight on a Monarch cycle ergometer [3].

The final testing session also took place at the University and began with a weight measurement again before the Biering-Sorensen test [5] was performed to assess the endurance of the spinal extensors. Maximum vertical jump height was then assessed as a measurement of lower-body power from a standing, two-footed take off with countermovement arm swing as outlined in the Sargent test protocol [18]. A $\mathrm{VO}_{2}$ max treadmill test was then 
performed to assess aerobic power. A ramp protocol was used in conjunction with a metabolic cart to measure breath-by-breath gas exchange while participants exerted maximum effort in running on the treadmill. Anaerobic threshold was also recorded by determining the inflection point of the $\mathrm{V}_{\mathrm{E}} / \mathrm{VO}_{2}$ curve (volume of air expired/volume of oxygen consumed).

\section{Statistical Analysis}

Data was presented as mean \pm standard deviation with ranges also given. Where appropriate, data was normalized to allow for comparison between people of different body sizes. Sub-analysis by decade-long age groups was also performed. Assumptions of statistical normality were checked using estimates of skewness and kurtosis as well as he Kolmogorov-Smirnov test. Statistical testing using SPSS 21 software comprised of Pearson's correlation coefficients and one-way ANOVAs for between group differences based on age. Statistical significance was set at the two-tailed $\mathrm{p}<0.05$ level.

\section{RESULTS}

Descriptive statistics of procedures performed, including mean, standard deviation, and range are displayed in Table 1. Of particular interest are some of the low-end ranges of some variables, such as with $\mathrm{VO}_{2} \max$. Though aerobic capacity averaged $42.2 \pm 6.6 \mathrm{ml} \mathrm{O}_{2} / \mathrm{kg} / \mathrm{min}$ for the group as a whole, one subject at the lower end of the data only reached $27.3 \mathrm{ml} \mathrm{O} / \mathrm{kg} / \mathrm{min}$.

Table 1. Baseline and physical fitness characteristics of firefighters

Subject number, mean, standard deviation, minimum, and maximum values for all data collected.

\begin{tabular}{lrrrrr}
\hline & N & Mean & SD & $\begin{array}{c}\text { Mini- } \\
\text { mum }\end{array}$ & $\begin{array}{c}\text { Maxi- } \\
\text { mum }\end{array}$ \\
\hline Age (years) & 49 & 40.5 & 8.3 & 26 & 55 \\
\hline Resting Heart Rate $(\mathrm{bpm})$ & 49 & 57.7 & 8.2 & 40 & 74 \\
\hline Resting Systolic Blood Pressure $(\mathrm{mm} \mathrm{Hg})$ & 49 & 121.5 & 11.9 & 100 & 149 \\
\hline Resting Diastolic Blood Pressure $(\mathrm{mm} \mathrm{Hg})$ & 49 & 71.5 & 9.9 & 48 & 96 \\
\hline Height $(\mathrm{cm})$ & 49 & 179.2 & 6.6 & 166.5 & 196.0 \\
\hline Weight $(\mathrm{kg})$ & 49 & 89.5 & 13.0 & 64.3 & 126.1 \\
\hline Body Mass Index $\left(\mathrm{kg} / \mathrm{m}^{2}\right)$ & 49 & 27.8 & 3.6 & 21.7 & 37.3 \\
\hline
\end{tabular}


Table 1. Continuation

\begin{tabular}{|c|c|c|c|c|c|}
\hline & $\mathbf{N}$ & Mean & SD & $\begin{array}{l}\text { Mini- } \\
\text { mum }\end{array}$ & $\begin{array}{l}\text { Maxi- } \\
\text { mum }\end{array}$ \\
\hline Waist Circumference $(\mathrm{cm})$ & 49 & 93.5 & 10.1 & 79 & 123 \\
\hline Body Fat (\%) & 49 & 24.2 & 5.4 & 14.7 & 37.9 \\
\hline CPAFLA Healthy Body Composition Score & 49 & 7.6 & 6.8 & 0 & 15 \\
\hline Functional Movement Screen (total score) & 49 & 15.6 & 1.6 & 11 & 19 \\
\hline $60^{\circ}$ Abdominal Endurance Test (s) & 24 & 153.8 & 94.2 & 64 & 407 \\
\hline Biering-Sorensen Test (s) & 23 & 113.4 & 48.6 & 24 & 231 \\
\hline ACSM Pushups (repetitions) & 49 & 31.4 & 11.6 & 8 & 60 \\
\hline Vertical Jump (cm) & 22 & 50.0 & 9.6 & 33 & 66 \\
\hline Quadriceps Strength $(\mathrm{Nm} / \mathrm{kg})$ & 24 & 3.0 & 0.7 & 1.9 & 4.2 \\
\hline Bicep Strength $(\mathrm{Nm} / \mathrm{kg})$ & 24 & 1.0 & 0.1 & 0.7 & 1.2 \\
\hline Wingate Test Peak Power (W/kg) & 24 & 10.6 & 1.1 & 8.5 & 12.3 \\
\hline Wingate Test Average Power (W/kg) & 24 & 7.4 & 1.0 & 5.2 & 8.8 \\
\hline Wingate Test Minimum Power (W/kg) & 24 & 5.3 & 1.0 & 3.5 & 6.7 \\
\hline Wingate Test Fatigue Index (\%) & 24 & 49.7 & 8.7 & 31.3 & 64.5 \\
\hline $\mathrm{VO}_{2} \max \left(\mathrm{ml} \mathrm{O}_{2} / \mathrm{kg} / \mathrm{min}\right)$ & 23 & 42.2 & 6.5 & 27.3 & 52.8 \\
\hline Anaerobic Threshold $\mathrm{VO}_{2}\left(\mathrm{ml} \mathrm{O}_{2} / \mathrm{kg} / \mathrm{min}\right)$ & 23 & 33.3 & 8.2 & 18.4 & 47.3 \\
\hline Anaerobic Threshold $\mathrm{VO}_{2}\left(\%\right.$ of $\left.\mathrm{VO}_{2} \max \right)$ & 23 & 78.1 & 11.5 & 57.0 & 96.0 \\
\hline
\end{tabular}

Correlations were performed to help ascertain which variables may best predict performance in most other variables. Pearson's $r$ correlation statistic was used because variables had a parametric distribution [12]. Body fat percentage had the greatest amount of significant correlations with other variables related to both performance and body composition (Table 2). Total score in the FMS displayed modest, negative correlations with many of the body composition variables (Table 3 ). Maximum vertical jumping height also exhibited strong, positive correlations with many of the performance tests administered (Table 4). 
Table 2. Correlations between body fat percentage and performance variables

\begin{tabular}{lcc}
\hline & $r$ Value & $p$ Value \\
\hline ACSM Pushups & -0.61 & $<0.001$ \\
\hline Quadriceps Strength & -0.58 & 0.003 \\
\hline Bicep Strength & -0.56 & 0.005 \\
\hline Wingate Test Peak Power & -0.55 & 0.005 \\
\hline Wingate Test Average Power & -0.62 & 0.001 \\
\hline Wingate Test Minimum Power & -0.51 & 0.012 \\
\hline Vertical Jump & -0.72 & $<0.001$ \\
\hline VO ${ }_{2}$ max & -0.44 & 0.037 \\
\hline Anaerobic Threshold $\mathrm{VO}_{2}$ & -0.53 & 0.009 \\
\hline
\end{tabular}

Table 3. Correlations between Functional Movement Screen total score and body composition variables

\begin{tabular}{lcc}
\hline & $r$ Value & $p$ Value \\
\hline Weight & -0.36 & 0.01 \\
\hline Body Mass Index & -0.48 & $<0.001$ \\
\hline Waist Circumference & -0.47 & 0.001 \\
\hline Body Fat Percentage & -0.48 & $<0.001$ \\
\hline $\begin{array}{l}\text { CPAFLA Healthy Body } \\
\text { Composition Score }\end{array}$ & 0.48 & 0.001 \\
\hline
\end{tabular}

Table 4. Correlations between vertical jump and performance variables

\begin{tabular}{lcc}
\hline & $r$ Value & $p$ Value \\
\hline ACSM Pushups & 0.58 & 0.005 \\
\hline Quadriceps Strength & 0.62 & 0.002 \\
\hline Bicep Strength & 0.73 & $<0.001$ \\
\hline Wingate Test Peak Power & 0.75 & $<0.001$ \\
\hline Wingate Test Average Power & 0.8 & $<0.001$ \\
\hline Wingate Test Minimum Power & 0.6 & 0.003 \\
\hline VO 2 max & 0.67 & 0.001 \\
\hline Anaerobic Threshold $\mathrm{VO}_{2}$ & 0.78 & $<0.001$ \\
\hline
\end{tabular}


One-way analysis of variance (ANOVA)s were performed to look for differences in $\mathrm{VO}_{2} \max$ and Wingate test peak power production based on differences in decade-long age groups did not yield significant results. However, $\mathrm{VO}_{2} \mathrm{max}$ did display a significant negative correlation with age (Figure 1).

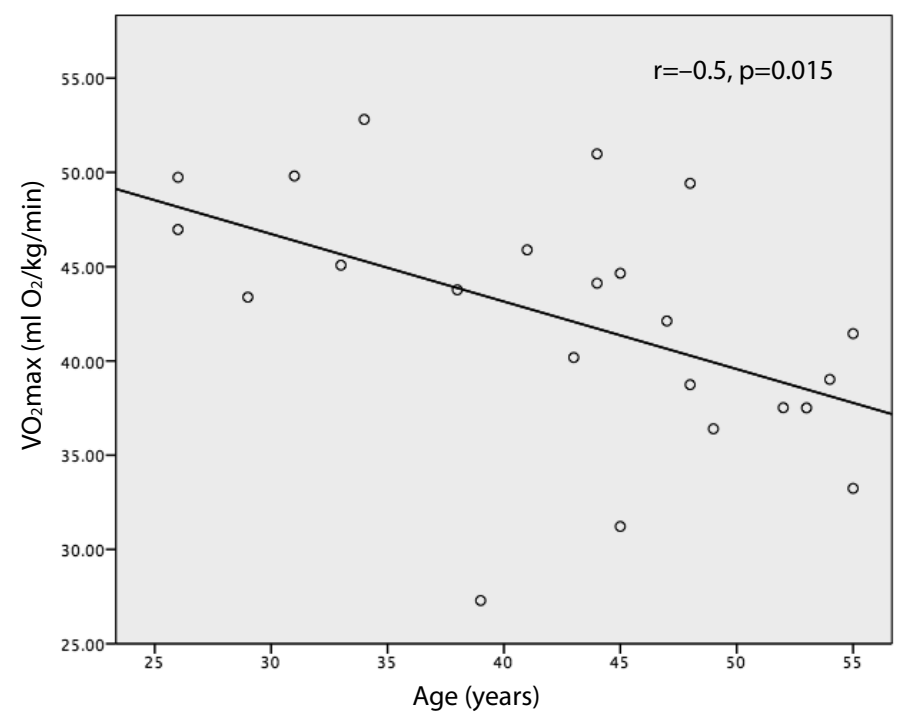

Figure 1. Relationship between $\mathrm{VO}_{2}$ max and age

Scatter plot of relative $\mathrm{VO}_{2} \max \left(\mathrm{ml} \mathrm{O}_{2} / \mathrm{kg} / \mathrm{min}\right.$ ) and age (years) of firefighters ( 22 male and 1 female). A negative correlation was found between $\mathrm{VO}_{2}$ max and age $(r=-0.5, p=0.015)$

\section{DISCUSSION}

The primary aim of this study was to collect data on physical fitness characteristics of front-line firefighters and in this regard it was found that there was a large range for many of the measures taken. While mean values are often similar to normative population data the wide range of data suggesting that a number of firefighters have lower performance in some measures than what might be optimal for the physical demands of front-line firefighting and are at times even lower than reference untrained age-matched cohorts. Correlation testing hinted at the potential for body fat percentage to be a predictor of both overall health and work performance. In addition, it was found that simple field tests such as pushups completed and vertical jump may form a modestly predictive testing battery for performance in some of the more technical and comprehensive tests, while abdominal endurance, back extensor endurance and FMS score may modestly correlate 
with future injury risk. It is possible that testing using these simple measures could potentially be performed annually by the fire departments to provide a crude assessment of overall front-line firefighter fitness and monitor performance in their firefighters. As a tertiary focus, it was recommended that based on these results, voluntary fitness training and testing programs could be put in place to combat the age-related decline in fitness and also that the development of training programs specific to the Kitchener Fire Department should focus primarily on aerobic fitness and spine and core stabilizing musculature.

$\mathrm{VO}_{2}$ max was found to be $42.2 \pm 6.5 \mathrm{ml} \mathrm{O}_{2} / \mathrm{kg} / \mathrm{min}$, superficially appearing very much in line with the standard previously established for firefighting of $42 \mathrm{ml} \mathrm{O}_{2} / \mathrm{kg} / \mathrm{min}[23,29]$. However, these results indicate that a significant portion of the sample tested fell below the established standard. Though this sample of firefighters tested better than reference adult males in the same age range $(38.1 \mathrm{ml} \mathrm{O} / \mathrm{kg} / \mathrm{min})$ [27], it is expected that those in a public safety profession such as firefighting would maintain a better fitness level than their counterpart in the population as there is a large physical fitness component to their job. It was also noteworthy that a number of subjects fell well below the mean with the lowest active firefighter having a maximum $\mathrm{VO}_{2}$ of only $27.3 \mathrm{ml} \mathrm{O}_{2} / \mathrm{kg} / \mathrm{min}$.

$\mathrm{VO}_{2}$ at the anaerobic threshold followed a similar pattern to $\mathrm{VO}_{2} \mathrm{max}$, such that it ranged from $18.4-47.3 \mathrm{ml} \mathrm{O}_{2} / \mathrm{kg} / \mathrm{min}$, and the two measures had a strong positive correlation $(\mathrm{r}=0.84, \mathrm{p}<0.001)$. The anaerobic threshold is a good predictor of actual sustained work performance [26], and looking at the lower value of $18.4 \mathrm{ml} \mathrm{O} / \mathrm{kg} / \mathrm{min}$ would correspond to only the equivalent work of a slow jog or brisk walk. This further highlights the possibility that a portion of this sample may not possess the requisite fitness level to adequately perform their job responsibilities.

Body fat percentage was found to be $24.2 \pm 5.4 \%$, correlated positively with many of the health-related measures, and negatively with some of the other performance tests. A secondary focus of the present study was to identify simple tests that might potentially predict performance in more complex tests and also to determine fitness variables that can serve as risk factors for on-the-job mortality. Body fat percentage addresses both of these applications as increased body fat may have been associated with impaired performance in almost all of the tests and possibly also reflected an increased risk for myocardial infarction as it is assumed to positively correlate with increased blood lipids [4]. Firefighters of similar age have previously been reported to be leaner [7] and normative population data indicates that the 
average $40-49$ year old male has only $21.9 \%$ body fat [1], so there is certainly room for improvement in this regard, especially when taking into account that firefighting is a public safety profession that places a premium on physical fitness.

While more research is needed to provide conclusive evidence, predictive testing batteries for both new and experienced firefighters could become a possibility to both monitor and assess both performance and future injury risk. Repetitions in the ACSM pushup test averaged 31.4 \pm 11.6 in this sample of firefighters which is quite similar to the previously reported data in this type of population of $35.6 \pm 15.3$ repetitions [21]. This result once again highlights the large range in the data and fitness levels of our front-line firefighter cohort as demonstrated by a standard deviation of over one third of the mean. Results in the pushup test correlated with dynamometer determined upper-body muscle peak torque $(r=0.62, p=0.001)$ and may therefore be used as a modestly accurate predictor of overall upper-body strength in a firefighter population. Maximum vertical jump height correlated with many of the more sophisticated performance measurements, including peak power produced during the Wingate test $(\mathrm{r}=0.75, \mathrm{p}<0.001)$ and $\mathrm{VO}_{2} \max (\mathrm{r}=0.67$, $\mathrm{p}=0.001$ ). Since the test can be administered with minimal training, equipment, and time it may suggested as a simple predictive test to monitor fitness in firefighters when more expensive and sophisticated testing may not be a feasible option.

Total score in the FMS for this group of firefighters was $15.6 \pm 1.5$ out of a possible 21 points. Lower scores indicate that one has compensations in their movement patterns which can lead to muscle imbalances and overuse injuries over time as other less-optimally designed or positioned muscle groups must work harder to compensate for weaker muscle groups [15, 30]. Firefighters who have been injured have previously been reported to score lower on the FMS than their injury-free counterparts [24] and firefighters who eventually sustained an injury during academy training scored significantly lower than those who did not in a pre-training FMS [6]. Performance in the $60^{\circ}$ abdominal endurance test averaged $153.8 \pm 94.2 \mathrm{~s}$ and $113.4 \pm 48.6$ $\mathrm{s}$ in the Biering-Sorensen test that assesses back extensor endurance. While this data has not been previously reported in the firefighter population, typical adult males have been reported to be able to hold the flexed position of the abdominal endurance test for an average of $144 \pm 76 \mathrm{~s}$ and the extended position of the Biering-Sorensen test for $146 \pm 51 \mathrm{~s}$ [20]. As with many of the other measures, the large standard deviations reported indicate a large range of data and suggest widely varying capacities in the sample of firefighters 
tested. The health of the torso, and specifically spine stabilizing musculature, are being increasingly implicated in injury risk and low-back pain and it has been suggested that maintaining a near 1.0 ratio between torso flexor and extensor muscle endurance time may be ideal for optimal health $[5,20]$. Together with the FMS, these three simple assessments may for the basis of some type of injury-risk screening program for fire departments in the future with additional research to better discern predictive value.

Firefighters are expected and encouraged to maintain their fitness level throughout their career, but the results of the present study suggest that there may be a significant portion of firefighters that are not sufficiently fit to perform their duties, and/or are only at or below par with a typical untrained adult male. Implementation of further formal fitness testing and training programs may be part of the solution. For example, a voluntary program similar to the Ontario Police Fitness Pin Award Program [25] could be developed where firefighters are given incentives to complete voluntary fitness testing ever 2-3 years and to participate in exercise training programs. In addition, based on the findings of the present study it was recommended that training programs for the Kitchener Fire Department should focus primarily on improving aerobic capacity as firefighters must be able to sustain a reasonably intense submaximal workload for many minutes at a time and there may be a subset of this population that does not possess adequate fitness to do so. Secondly, core and spine stabilizing musculature was also identified as an area of weakness in this group and it would be prudent to include abdominal and back musculature strengthening exercises in a training program for the sake of overall health and injury reduction. Power, strength, and muscular endurance tasks were performed reasonably well by this sample of firefighters. These areas should still be trained, but more time should be focused on the previous two areas identified as priorities.

While this study makes important and novel contributions to the literature available on the physical fitness of active firefighters, it is important to acknowledge that the small sample size and specifically, the completion rate of testing limits the ability to generalize the results to all firefighters in this or other firefighter populations. In addition a lack of adequate numbers of females in the sample group did not allow for sub-analysis by gender to determine if fitness characteristics differ between the sexes. It may also be possible that since, the relatively more fit firefighters may have been more likely to volunteer and complete this type of testing, that the results of this study may actually over-estimate the fitness of a typical front-line firefighter cohort. 
In summary, front-line firefighters possess a large range of physical fitness levels. In many instances this sample's mean values were similar to or above pre-established standards or normative population data. However, the results indicate that close to half of the firefighters population tested fell below established firefighter standards or in tests where such standards had not been established, fell at or below reference untrained adult men. This is certainly cause for concern as there may be a significant portion of firefighters who do not possess an adequate fitness level to safely perform the job responsibilities expected of them.

\section{REFERENCES}

1. Thompson WR, Gordon NF, P.L.S. (eds) (2010) ACSM's Guidelines for Exercise Testing and Prescription (8th ed). Lippincott Williams \& Wilkins

2. Antonopoulos J, Gillquist J. (1996) Anterior tibial translation related to isokinetic concentric quadriceps torques. Isokinetics and Exercise Science, 6 (2): $145-51$

3. Ayalon A, Inbar O, Bar-Or O. (1974) Relationships among measurements of explosive strength and anaerobic power. In: Nelson R, Morehouse C (eds). Biomechanics IV: Proceedings of the Fouth International Seminar on Biomechanics. Baltimore: University Park Press, 572-577

4. Baur DM, Christophi CA, Tsismenakis AJ, Cook EF, Kales SN. (2011) Cardiorespiratory fitness predicts cardiovascular risk profiles in career firefighters. J Occup Environ Med, 53 (10): 1155-1160

5. Biering-Sorensen F. (1984) Physical measurements as risk indicators for lowback trouble over a one-year period. Spine, 9 (2): 106-119

6. Butler RJ, Contreras M, Butron L, Plisky PJ, Kiesel KB. (2011) Functional movement screen and physical performance scores during a firefighter academy: implications for injury screening. Med Sci Sports Exerc, 43 (S1): 795

7. Calavalle AR, Sisti D, Mennellli G, Andolina G, Del Sal M, Rocchi MB L, Benelli P, Stocchi V. (2013) A simple method to analyze overall individual physical fitness in firefighters. J Strength Cond Res, 27 (3): 769-775

8. Canadian Society for Exercise Physiology. (1997) The Canadian Physical Activity, Fitness and Lifestyle Appraisal

9. Chisholm D, Collis M, Kulak L, Davenport W, Gruber N. (1975) Physical Activity Readiness. British Columbia Medical Journal, 17: 375-378

10. City of Toronto. (2012) Toronto Fire Services Recruitment - Operations Firefighter. Retrieved from http://www.toronto.ca/fire/recruitment/pf.htm

11. Durnin JVGA, Womersley J. (1974) Body fat assessed from total body density and its estimation from skinfold thickness: measurements on 481 men and women aged from 16 to 72 years. Br J Nutr, 32: 77-97 
12. Field A. (2009) Discovering Statistics using SPSS (3rd ed.). London: SAGE Publications Ltd

13. Kales SN, Soteriades ES, Christophi CA, Christiani DC. (2007) Emergency duties and deaths from heart disease among firefighters in the United States. NEJM, 356 (12): 1207-1215

14. Keys A. (1956) Recommendations concerning body measurements for the characterization of nutritional status. Hum Biol, 28 (2): 111-123

15. Kiesel K, Plisky PJ, Voight ML. (2007) Can serious injury in professional football be predicted by a preseason functional movement screen? N Am J Sports Phys Ther, 2 (3): 147-158

16. Kvist J, Karlberg C, Gerdle B, Gillquist J. (2001) Anterior tibial translation during different isokinetic quadriceps torque in anterior cruciate ligament deficient and nonimpaired individuals. J Orthop Sports Phys Ther, 31 (1): 4-15

17. Lusa S, Louhevaara V, Smolander J, Kivimaki M, Korhonen O. (1993) Physiological responses of firefighting students during simulated smoke-diving in the heat. Am Ind Hyg Assoc J, 54 (5): 228-34

18. Markovic G, Dizdar D. (2004) Reliability and factorial validity of squat and countermovement jump tests. J Strength Cond Res, 18 (3): 551-555 jscr/ Abstract/2004/08000/Reliability_and_Factorial_Validity_of_Squat_and.28.aspx

19. Mason C, Katzmarzyk P. (2010) Waist circumference thresholds for prediction of cardiometabloic risk: is measurement site important? Eur J Clin Nutr, 64 (8): 862-867

20. McGill SM, Childs A, Liebenson C. (1999) Endurance times for low back stabilization exercises: clinical targets for testing and training from a normal database. Arch Phys Med Rehabil, 80 (8): 941-944

21. Michaelides MA, Parpa KM, Thompson J, Brown B. (2008) Predicting performance on a firefghter's ability test from fitness parameters. Res Q Exerc Sport, 79 (4): 468-475

22. Misner JE, Boileau RA, Plowman SA, Elmore BG, Gates MA, Gilbert JA, Horswill C. (1988) Leg power characteristics of female firefighter applicants. J Occup Med, 30 (5): 433-437

23. O'Connell ER, Thomas PC, Cady LD, Karwasky RJ. (1986) Energy costs of simulated stair climbing as a job-related task in fire fighting. J Occup Med, 28 (4): 282-284

24. Peate W, Bates G, Lunda K, Francis S, Bellamy K. (2007) Core strength: a new model for injury prediction and prevention. J Occup Med Toxicol, 2: 3

25. Police Fitness Personnel Ontario (2014) Ontario Police Fitness Pin Award Program. Retrieved from http://www.pfpo.org/index.php/2013-01-12-19-0053/ontario-police-fitness-pin-award-program

26. Powers SK, Howley ET. (2012) Exercise Physiology: Theory and Application to Fitness and Performance (8th ed). New York, USA: McGraw-Hill 
27. Ratamess N. (2012) ACSM's Foundations of Strength Training and Conditioning. New York, USA: Lippincott Williams \& Wilkins

28. Rodríguez-Marroyo JA, Villa JG, López-Satue J, Pernía R, Carballo B, GarcíaLópez J, Foster C. (2011) Physical and thermal strain of firefighters according to the firefighting tactics used to suppress wildfires. Ergonomics, 54 (11): 1101-1108

29. Sothmann MS, Saupe K, Jasenof D, Blaney J. (1992) Heart rate response of firefighters to actual emergencies, implications for cardiorespiratory fitnes. J Occup Med, 34 (8): 797-800

30. Teyhen DS, Shaffer SW, Lorenson CL, Halfpap JP, Donofry DF, Walker MJ, Dugan JL, Childs JD. (2012) The Functional Movement Screen: a reliability study. J Orthop Sports Phys Ther, 42 (6): 530-540

31. Wynn P, Hawdon P. (2012) Cardiorespiratory fitness selection standard and occupational outcomes in trainee firefighters. Occup Med (Lond), 62 (2): 123128

\section{Correspondence to:}

Peter M. Tiidus PhD

Professor and Dean

Faculty of Applied Health Sciences

Brock University

St. Catharines, ON Canada L2S3A1

peter.tiidus@brocku.ca 